\title{
INDICADORES
}

\section{THE NEXT BIBLIOMETRICS: ALMETRICS (AUTHOR LEVEL METRICS) AND THE MULTIPLE FACES OF AUTHOR IMPACT}

\author{
La bibliometría que viene: ALMetrics (Author Level \\ Metrics) y las múltiples caras del impacto de un autor
}

Enrique Orduña-Malea, Alberto Martín-Martín and Emilio Delgado-López-Cózar

Nota: Este artículo puede leerse traducido al español en

http://www.elprofesionaldelainformacion.com/contenidos/2016/may/18_esp.pdf

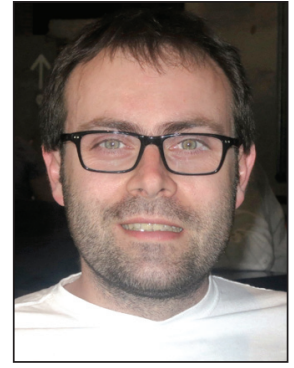

Enrique Orduña-Malea holds a PhD in library \& information science (honored with an extraordinary doctorate award) from the Polytechnical University of Valencia (UPV), where he works as a postdoctoral researcher. He belongs to the EC3 Research Group at the University of Granada as well as to the Trademetrics Group at UPV. His main research interests are centered on webometrics and bibliometrics, with a focus on ranking design, web sources, and indicators, and the use of these tools in academic and commercial evaluation projects.

http://orcid.org/0000-0002-1989-8477

Universitat Politècnica de València, Facultad de Informática Camí de Vera, s/n. 46020 Valencia, España enorma@upv.es

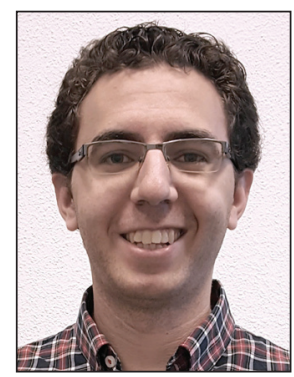

Alberto Martín-Martín holds a BSc degree in library and information science, and a MSc degree in scientific information and communication from the University of Granada. He received the national award for excellence in academic performance (social sciences) in 2013. He is a member of the EC3 Research Group and works as a PhD student in bibliometrics and scientific communication projects; he is currently enjoying a four-year doctoral fellowship at the University of Granada. http://orcid.org/0000-0002-0360-186X

Universidad de Granada, Facultad de Comunicación y Documentación Campus de Cartuja, s/n. 18071 Granada, España albertomartin@ugr.es



Emilio Delgado-López-Cózar is a professor of research methods at the Department of Communication and Information, University of Granada, and a founding member of the EC3 Research Group (Evaluación de la Ciencia y de la Comunicación Científica). Throughout his life he has created a wide range of scientific assessment tools, such as: $h$ Index Scholar, IN-RECS, IN-RECJ, IN-RECH (citation index of Spanish journals in the social sciences, legal sciences, and humanities), Journal Scholar Metrics, $\mathrm{H}$ index Spanish journals according to Google Scholar Metrics, Scholar Mirrors, Co-author Index, Publishers Scholar Metrics, Book Publishers Library Metrics, Classic Scholar's Profiles, RESH (Spanish Journals of Social Sciences and Humanities), CIRC (Integrated Classification of Scientific Journals), Ranking I-UGR of Spanish Universities, EC3 Metaranking of Spanish Universities, Cientifica, and others.

http://orcid.org/0000-0002-8184-551X

Universidad de Granada, Facultad de Comunicación y Documentación Campus de Cartuja, s/n. 18071 Granada, España edelgado@ugr.es

\section{Abstract}

The main goal of this article is to describe the purpose and content of a new branch of bibliometrics: ALMetrics (AuthorLevel Metrics). ALMetrics is focused on the quantitative analysis of an author's performance by measuring the dimensions of their intellectual activity as shown through varied metric indicators. This article will list, define, and classify the different 
metrics that are offered in newer information portals that showcase the scientific activity of authors. These metrics are grouped into five sets: bibliometrics (publication and citation), usage, participation, rating, social connectivity, and composite indicators. This new bibliometric specialty is necessary because of new trends in scientific assessment, which have moved analysis away from old bibliometrics (based on journal analysis and Impact Factor) towards new bibliometrics that analyze both documents and authors via a mix of indicators. Most importantly, ALMetrics responds to the researchers' desire for both knowledge and acknowledgement.

\section{Keywords}

ALMetrics; Author-level metrics; Altmetrics; Scientific evaluation; Social academic networks; Bibliometrics.

\section{Resumen}

La principal meta de este trabajo es fijar el objeto y contenido de una nueva rama de la bibliometría, a la que denominamos ALMetrics (Author Level Metrics), que está centrada en el análisis cuantitativo del rendimiento de los autores científicos a través de la medición de todas las dimensiones de su actividad intelectual con los más variados indicadores métricos. El trabajo se dirige específicamente a listar, definir y clasificar las diferentes métricas que se ofrecen a día de hoy en los nuevos portales de información creados para mostrar la actividad científica de los autores. Se agrupan las métricas en siete conjuntos: publicación, citación, uso, participación, valoración, conectividad social y combinados. Se justifica el nacimiento de esta nueva especialidad bibliométrica en las nuevas tendencias que se avizoran en la evaluación científica, y que nos transportan desde una vieja bibliometría (basada en el análisis de la revista y la utilización del factor de impacto como indicador estrella) hacia una nueva bibliometría basada directamente en el análisis de los documentos y los autores a través de un crisol de indicadores que se alimentan no sólo de la avidez de los investigadores por el conocimiento, sino por el reconocimiento.

\section{Palabras clave}

Métricas de autor; Altmétricas; Evaluación científica; Redes sociales académicas; Bibliometría.

Orduña-Malea, Enrique; Martín-Martín, Alberto; Delgado-López-Cózar, Emilio (2016). "The next bibliometrics: ALMetrics (Author Level Metrics) and the multiple faces of author impact". El profesional de la información, v. 25, n. 3, pp. 485-496.

http://dx.doi.org/10.3145/epi.2016.may.18

\section{The old bibliometrics}

Eugene Garfield laid the foundations of the field of bibliometrics when he created the Impact Factor (Garfield; Sher, 1963), which marked the beginning of the era of citation analysis. In time, this indicator was joined by the Science Citation Index (1964), the Social Sciences Citation Index (1972), and the Arts \& Humanities Citation Index (1978). All these products were designed with the same philosophy in mind and are described herein:

\subsection{Journals: the lenses of the old bibliometrics}

The unit of analysis has always been the journal. The former ISI (Institute for Scientific Information) started publishing the now famous Journal Citation Reports (JCR) by ranking journals according to their Impact Factor (IF). Two editions were published every year, one for journals in the natural sciences and another for social science journals. These rankings became the main tool by which the performance of all dimensions of scientific activity were evaluated. The worth of an author or an institution was equal to the worth of the journals where their studies were published.

Both the article, the author, and the author's home institution automatically inherited the Impact Factor of the publishing journal, as if the Impact Factor was a genetic trait that could be passed down. Even though it was proven that the Impact Factor of a journal did not accurately reflect the impact of each individual article (Seglen, 1997), many rankings (especially university rankings), as well as institutional and national evaluation systems, continued using the Impact Factor in their selection and promotion processes.

Both the article, the author, and the author's home institution automatically inherited the Impact Factor of the publishing journal, as if the Impact Factor was a genetic trait that could be passed down

\subsection{The Impact Factor (IF): the ruler of the old biblio- metrics}

The unit of measure for scientific performance has been the IF, the bibliometric indicator par excellence. It was originally designed as a tool to select the journals to be indexed in the Science Citation Index (SCI), and Garfield, its creator, has repeatedly declared it should not be used to assess researchers or institutions (Garfield, 2006). In addition, dozens of modifications and alternative indicators have been proposed over the years to replace it. In spite of all this, the IF became the gold standard of bibliometrics.

The emergence of other citation databases (Scopus) and indicators (Eigenfactor, SNIP, SJR, Crown, etc.) has not altered this situation. Only the h-index, designed by Hirsch (2005) 
to measure the performance of authors (although its use was later extended to assess journals and institutions), has challenged the domination of the IF, subsequently making it lose part of its predominant position.

It seems that criticism from DORA (Declaration on Research Assessment ${ }^{1}$ ) has taken its toll on this indicator, and these days the trend is to criticize the IF indiscriminately. At the risk of going against this current, we would like to recognize that, although it is clear that this indicator has been misused more often than not, the IF achieved the commendable goal of separating the wheat from the chaff (identifying influential journals), and that it should be kept in use as an indicator to measure competitiveness and reputation. That is, the ability of an author or institution to publish in journals with high demand for publication.

\section{A new bibliometrics is arising, one that is marked by a shift in the unit of analysis and a torrent of new units of measurement}

The entire framework in which the old bibliometrics was based has been severely disrupted by the emergence of new information and communication technologies at the end of the $20^{\text {th }}$ century-technologies that are now well-established. The widespread adoption of information creation and dissemination tools on the Web makes it possible for any person, regardless of technical skills, to publish his/her own content and make it available to anyone with access to the Internet.

The appearance of large knowledge storage platforms like repositories (both disciplinary and institutional) where authors can store their works permanently, academic search engines that automatically index everything that is loaded onto the academic Web (mainly Google Scholar), and webbased reference managers (like Mendeley or CiteULike), are enabling a new model of scientific communication, and with it, new ways to publish and disseminate research results.

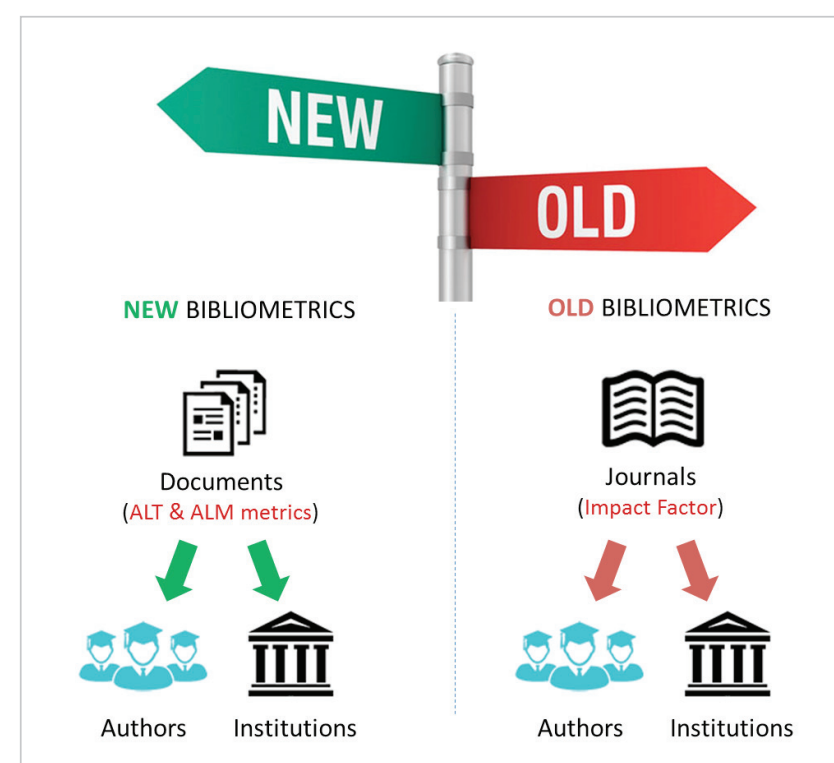

Figure 1. Changes in the unit of analysis in the new bibliometrics
The advent of web 2.0, or social web, was the icing on the cake of this new communication system, thanks to the myriad of communication tools it enabled. Among these tools there were blogging platforms (Blogger, Wordpress), microblogs (Twitter), and social networks, including those designed for the general public (Facebook), for professional purposes (LinkedIn), and for academics (ResearchGate and Academia.edu). These tools make it much easier for a published document to reach its potential target audience.

\section{The new bibliometrics: new mirrors, new rules}

Over the rubble of the old Bibliometrics, and boosted by these new means of communication, a new bibliometrics is arising, one that is marked by a shift in the unit of analysis and a torrent of new units of measurement (DelgadoLópez-Cózar 2014):

\subsection{The mirrors of the new Bibliometrics: documents and people}

Documents and authors themselves have become the object of evaluation. This progressive development and adoption of platforms that collect and display author data are putting researchers in the crosshairs, effectively turning them into the new targets of scientific evaluation. Among the platforms that are contributing to this shift, we can find: bibliographic and bibliometric profile services (ResearcherID, Google Scholar Citations, Microsoft Academic Search, Scopus Author ID, ResearchGate, Mendeley, Academia.edu, Linkedln); profiles generated by disciplinary repositories (CitEc in RePEC) ${ }^{2}$ or institutional repositories (Futur in the Polytechnic University of

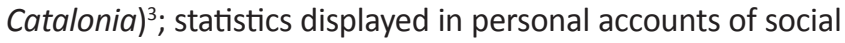
networks, whether they be general (Twitter) or specifically designed to share content (presentations in SlideShare and videos in YouTube); and web apps like ImpactStory ${ }^{4}$.

The digital footprint is wide and is not limited to scientific documents, it also includes social activities and interactions that scientists, like any other citizen of the Web, can engage with on a daily basis

In short, new platforms are true mirrors that reflect the intellectual life of an author, his/her scientific and academic production, as well as the impact of that production in the scientific, academic, professional, and social communities. The information displayed by each platform will depend on its document coverage, its user base (size and demographic composition: scientific or professional, specific disciplines, etc.), and the features it provides (both social and bibliographic).

\subsection{The rulers of the new Bibliometrics: multiple and varied indicators from multiple sources}

A multiplicity of new bibliometric indicators is now available. The new bibliometrics take advantage of all the information that is generated in the Web, in the broadest sense of the term. Documents stored on the Web can be visited, visualized, downloaded, linked, shared, cited, reviewed, 
mentioned, commented, discussed, referenced, tagged, rated, followed, disseminated, etc. The digital footprint is wide and is not limited to scientific documents, it also includes social activities and interactions that scientists, like any other citizen of the Web, can engage with on a daily basis.

Therefore, these indicators will presumably be able to capture the scientific, educational, professional, and media impact of documents and authors. They can be applied to all kinds of disciplines (including basic and applied sciences, and ranging from science, technology and medicine to social sciences and humanities), document typologies (journal articles, books, technical reports, theses, dissertations, teaching materials, essays, comments on social media and mass media, patents, software, datasets, etc.), countries (dependent on the degree of penetration of the platform in each country), and languages in which science is communicated. The indicators can be applied at the document or author level, and later they can be aggregated by institution or subject domain.

\section{Author-Level Metrics: the academic soul}

It's in the juxtaposition of these new mirrors and indicators where this brand new branch of bibliometrics that we call ALMetrics (Author-Level Metrics) can be found. In this paper we try to define and outline its shape, and enumerate its indicators. This term, Author-Level Metrics, has been circulating in the scientific literature for the last couple of years (Das, 2015; Wildgaard et al., 2014; Wildgaard, 2015), and there is even an entry about it on Wikipedia ${ }^{5}$.

The ALMetrics we propose here should be included in the Altmetrics movement, the latest trend in the bibliometric world (Martín-Martín et al., 2016; DelgadoLópez-Cózar; Martín-Martín, 2016). The publication of the Altmetric Manifesto ${ }^{6}$ in 2010 brought to many researchers' attention the need to make use of the information that new social platforms were collecting, although the main focus of this movement was placed on measuring documents (the new preferred unit of analysis) directly. The movement was established on two principles:

- The impact of an article should not be restricted to the citations it receives from other articles indexed in certain bibliographic databases.

- Journal articles are not the only documents that make an impact on academia. There are other kinds of documents that may potentially have a quantifiable impact in the academic world (presentations, software, datasets, etc.).

Although some of the platforms that offer altmetric data put their focus on researchers from the outset (mainly ImpactStory), it has only been recently that these new indicators have started to be applied directly to authors via their online social profiles (Das, 2015). This development provides evidence that there is a shift from evaluations based solely on citation indicators (at the journal level) to an evaluation based on broader impact indicators (not restricted to citations) at the document and author levels.

The nature of these Author-Level Metrics is complex and diverse. They comprise traditional bibliometric indicators (Wildgaard et al., 2014; Wildgaard, 2015), as well as usage, dissemination, rating, and social connectivity indicators.

Table 1 shows a compilation of 93 ALMetrics, including a brief description of each one. Only the metrics concerning the documents included in the personal profiles of the main platforms that offer these features are considered. 
Table 1. Compilation of ALMetrics (publication, citation, use, dissemination, comment or discussion, rating, social connectivity, and composite indicators). ACA: Academia.edu; ALT: Altmetric.com; AZ: Amazon; GDR: GoodReads; CR: CrossRef; CUL: CiteUlike; DEP: Depsy; DLC: Delicious; DR; Dryad; DSP: dSpace; EP: ePrints; FCB: Facebook; FIG: Figshare; G+: Google+; GH: GitHub; GSC: Google scholar citations; IMP: ImpactStory; LK: LinkedIn; MAS: Microsoft academic search; MEND: Mendeley; OR: Orcid; PLUM: Plum analytics; PMC: PubMed Central; RED: Reddit; RG: ResearchGate; RID: ResearcherID; SCO: Scopus; SAID: Scopus author ID; SEMSCH: Semantic scholar; SLI: Slideshare; TW: Twitter; VI: Vimeo; WC: WorldCat; WK: Wikipedia; WOS: Web of science; YT: YouTube.

\begin{tabular}{|c|c|c|c|c|}
\hline \multirow[b]{2}{*}{$\mathbf{N}$} & \multicolumn{4}{|c|}{ PUBLICATION } \\
\hline & INDICATOR & DEFINITION & SOURCE OF DATA & $\begin{array}{l}\text { PLATFORM DIPLAYING } \\
\text { THE DATA }\end{array}$ \\
\hline 1 & $\begin{array}{l}\text { Publications } \\
\text { (automatic) }\end{array}$ & Publications of an author, automatically indexed & GSC, MAS, OR, WOS & GSC, MAS, OR, RID, SAID \\
\hline 2 & $\begin{array}{l}\text { Publications } \\
\text { (manual) }\end{array}$ & Publications and author has manually deposited & $\begin{array}{c}A C A, D R, F I G, G H, M E N D \\
R G\end{array}$ & $\begin{array}{l}A C A, D R, F I G, G H, I M P^{* * *} \\
\quad M E N D, P L U M, R G\end{array}$ \\
\hline 3 & Type of publication & $\begin{array}{l}\text { Items by type of publication (presentations, videos, } \\
\text { software, etc.) }\end{array}$ & & $R G, I M P^{* *}$ \\
\hline 4 & Co-authors & $\begin{array}{l}\text { Number of co-authors with whom the author has col- } \\
\text { laborated }\end{array}$ & $A C A$ & $A C A$ \\
\hline 5 & Open science triathlete & $\begin{array}{l}\text { Number of an author has published at least one Open } \\
\text { Access paper, an open dataset, and open source soft- } \\
\text { ware }\end{array}$ & Various sources & $I M P^{* * *}$ \\
\hline 6 & Posts & Posts an author has published & $G+, L K$ & $G+, L K$ \\
\hline 7 & Slides & Presentations an author has uploaded & $S L I$ & $S L I$ \\
\hline 8 & Software & Projects an author has created & GH & GH \\
\hline 9 & Tweets & Tweets an author has published & $T W$ & $T W$ \\
\hline 10 & Videos & Videos an author has uploaded & $Y T, V I$ & $Y T, V I$ \\
\hline
\end{tabular}

\begin{tabular}{|c|c|c|c|c|}
\hline \multirow[b]{2}{*}{$\mathbf{N}$} & \multicolumn{4}{|c|}{ CITATION } \\
\hline & INDICATOR & DEFINITION & SOURCE OF DATA & $\begin{array}{l}\text { PLATFORM DIPLAYING } \\
\text { THE DATA }\end{array}$ \\
\hline 11 & Total self-citations & Self-citations by an author & CitEc & CitEc \\
\hline 12 & Citations per year & Citations an author has received, per year & GSC, SEMSCH & GSC, SEMSCH \\
\hline 13 & Citations from editorials & Citations received from editorial articles & $P M C$ & $I M P^{*}$ \\
\hline 14 & Citations from reviews & Citations received from review articles & $P M C$ & $I M P^{*}$ \\
\hline 15 & $\begin{array}{l}\text { Average citations per } \\
\text { year }\end{array}$ & Average number of citations an author receives yearly & CitEc & CitEc \\
\hline 16 & $\begin{array}{l}\text { Average citations per } \\
\text { article }\end{array}$ & $\begin{array}{l}\text { Average number of citations an author receives per } \\
\text { article }\end{array}$ & $R I D, P M C$ & $R I D, I M P^{*}$ \\
\hline 17 & Total citations & Times an author's articles have been cited & $\begin{array}{l}A C A, C R, G S C, S C O, M A S \\
R G, S C O, S S R N, \text { USPO, WOS }\end{array}$ & $\begin{array}{l}A C A, G S C, I M P^{*}, M E N D \\
\text { MAS, PLUM, RID, RG, }\end{array}$ \\
\hline 18 & Citing documents & $\begin{array}{l}\text { Documents in which an author's works are cited at least } \\
\text { once }\end{array}$ & SCO & SAID \\
\hline 19 & h-index & $\begin{array}{l}\text { Highest number } h \text { of an author's papers that have } \\
\text { received at least } h \text { citations }\end{array}$ & $A C A, G S C, R G, S C O$, WOS & $\begin{array}{c}A C A, G S C, M E N D, R I D, R G \\
\text { SAID }\end{array}$ \\
\hline 20 & $h$-index (last 5 years) & $\begin{array}{l}\text { h-index, but only considering citations received in the } \\
\text { last } 5 \text { years }\end{array}$ & GSC & GSC \\
\hline 21 & $\begin{array}{l}h \text {-index (without self- } \\
\text { citations) }\end{array}$ & h-index excluding self-citations & $R G$ & $R G$ \\
\hline 22 & i10 index & Publications with at least 10 citations & CitEc, GSC & CitEc, GSC \\
\hline 23 & $\begin{array}{l}\text { i10 index (last five } \\
\text { years) }\end{array}$ & $\begin{array}{l}\text { i10 index, but only considering citations received in the } \\
\text { last } 5 \text { years }\end{array}$ & GSC & GSC \\
\hline 24 & Impact Points & $\begin{array}{l}\text { Sum of the impact factors of the journals where the } \\
\text { author has published articles }\end{array}$ & $R G$ & $R G$ \\
\hline 25 & Cited items & Articles that have received at least one citation & WOS & $R I D$ \\
\hline
\end{tabular}




\begin{tabular}{|c|c|c|c|c|}
\hline \multirow[b]{2}{*}{$\mathbf{N}$} & \multicolumn{4}{|c|}{ USAGE } \\
\hline & INDICATOR & DEFINITION & SOURCE OF DATA & $\begin{array}{l}\text { PLATFORM DIPLAYING } \\
\text { THE DATA }\end{array}$ \\
\hline 26 & Abstract views & Times an abstract has been visited & $\begin{array}{l}D S P, E B S C O, E P, P L O S \\
\text { RePEC }\end{array}$ & PLUM \\
\hline 27 & Actions/Engagement & Times an item has been interacted with in any way & $S L I, T W$ & $S L I, T W$ \\
\hline 28 & $\begin{array}{l}\text { Bookmarks } \\
\text { (automatic) }\end{array}$ & Times an author's items are bookmarked & $\begin{array}{l}\text { CUL, } \\
\text { DLC, SLI }\end{array}$ & $C U L, I M P^{*}, S L I, P L U M$ \\
\hline 29 & Clicks & Times an item is clicked & $S L I, T W$ & $S L I, T W$ \\
\hline 30 & Clicks URL & Times the URL of a resource is clicked & bit.ly, FCB & PLUM \\
\hline 31 & Downloads & Times an author's items have been downloaded & $D R, F I G, S L I$ & $D R, F I G, I M P^{*}, P L U M, S L I$ \\
\hline 32 & Exports/Saves & $\begin{array}{l}\text { Times a user has saved the bibliographic reference of } \\
\text { an author's document to a reference manager, sent it by } \\
\text { e-mail or printed it. The full-text of the document may or } \\
\text { may not be included in the reference. }\end{array}$ & EBSCO & PLUM \\
\hline 33 & Figure views & Times a certain figure in an article has been visualized. & FIG, PLOS & PLUM \\
\hline 34 & Forks & $\begin{array}{l}\text { Times a project has been forked (copied and used as a } \\
\text { starting point for other projects) }\end{array}$ & GH & $G H, I M P^{*}$ \\
\hline 35 & Holdings & Libraries that have a copy of a document & $W C$ & PLUM \\
\hline 36 & Links & Links to a document & StackExchange, WK & PLUM \\
\hline 37 & Links out & $\begin{array}{l}\text { Times an outlink leading to a catalog or link resolver is } \\
\text { clicked }\end{array}$ & Ebsco & PLUM \\
\hline 38 & Profile views (recent) & Recent visits to an author's profile (last week, month...) & $A C A, L K, R G$ & $A C A, I M P^{*}, L K, R G$ \\
\hline 39 & Profile views (total) & Visits to an author's profile & & $A C A, L K, R G, T W$ \\
\hline 40 & Q\&A links & Links found in all the StackExchange Q\&A communities & StackExchange Q\&A & $A L T$ \\
\hline 41 & Reads (Saves) & $\begin{array}{l}\text { Times users have saved an author's documents to their } \\
\text { personal libraries }\end{array}$ & CUL, GDR, MEND & CUL, MEND, PLUM \\
\hline 42 & Readerships typology & $\begin{array}{l}\text { Users that have added a document to their MEND } \\
\text { library, classified by academic status, country, and } \\
\text { discipline (top 3) }\end{array}$ & MEND & MEND, IMP* \\
\hline 43 & Replies & Answers received & $T W$ & $T W$ \\
\hline 44 & RG Reads & $\begin{array}{l}\text { Sum of the number of lectures of the summary, online } \\
\text { lectures, downloads and private shares of an author. }\end{array}$ & $R G$ & $R G$ \\
\hline 45 & Unique visitors & Unique visitors to an author's profile & $A C A$ & $A C A$ \\
\hline 46 & Usermentions & Times an author's profile has been mentioned & $T W$ & $T W$ \\
\hline 47 & $\begin{array}{l}\text { Views/Plays/ } \\
\text { impressions }\end{array}$ & $\begin{array}{l}\text { Times an author's documents have been visualized or } \\
\text { played }\end{array}$ & $\begin{array}{l}\text { DR, DSP, EBSCO, EP, FIG, } \\
\text { PLOS, Sciencedirect, SLI, } \\
\quad T W, V I, Y T\end{array}$ & $\begin{array}{l}\text { DR, FIG, IMP*, MEND, } \\
P L U M, S L I, T W, V I, Y T\end{array}$ \\
\hline
\end{tabular}

\section{DISSEMINATION, COMMENTS, DISCUSSION}

$\mathbf{N}$ INDICATOR

\section{DEFINITION}

All publications by an author since 2012 have been mentioned at least once

48 Clean sweep

49 Comments

50 Economic Blog Mentions

$51 \quad$ First steps

52 Follower frenzy

53 Forum Topic Count

54 Global reach

55 Global South
Comments received

Blogs that mention a document, inside the discipline of economics

At least some publications by an author have been mentioned online

Followers of the user with the highest number of Twitter followers that has mentioned one of an author's works. Percentile is also displayed.

Threads in a forum that discuss a document

Countries in which an author's work has been mentioned. Percentile is also displayed.

Percentage of online mentions coming from users living in the Southern Hemisphere. Percentile is also displayed.

\section{SOURCE OF DATA}

PLATFORM DIPLAYING THE DATA

\section{Various sources}

Reddit, SLI, YT, VI

Lists of blogs curated by PlumX

Various sources

TW

VI

Various sources

Various sources
$I M P^{* * *}$

SLI, IMP*, PLUM YT, VI

PLUM

$I M P^{* * *}$
PLUM

$I M P^{* * *}$

$I M P^{* * *}$ 


\begin{tabular}{|c|c|c|}
\hline 56 & Greatest hit & $\begin{array}{l}\text { Online mentions an author's most mentioned work has } \\
\text { received. Percentile is also displayed. }\end{array}$ \\
\hline 57 & Hot streak & $\begin{array}{l}\text { Consecutive months in which an author's works have } \\
\text { been mentioned online. Percentile is also displayed. }\end{array}$ \\
\hline 58 & Labmates & $\begin{array}{l}\text { Percentage of online mentions that come from resear- } \\
\text { chers. Percentile is also displayed. }\end{array}$ \\
\hline 59 & Mentions & $\begin{array}{l}\text { Times an author has been mentioned in various plat- } \\
\text { forms }\end{array}$ \\
\hline 60 & News & Mentions of an author's document in mass media \\
\hline 61 & Open sesame & $\begin{array}{l}\text { Gold Open Access publications an author has published. } \\
\text { Percentile is also displayed }\end{array}$ \\
\hline 62 & $\begin{array}{l}\text { Policy } \\
\text { documents }\end{array}$ & $\begin{array}{l}\text { Mentions to an author's documents in policy documents } \\
\text { (regulations, guidelines) }\end{array}$ \\
\hline 63 & Retweets & Retweets to an author's tweets \\
\hline 64 & Shares (automatic) & Times an author's documents have been shared \\
\hline 65 & Shares (manual) & Shares through the aggregation of article-level metrics \\
\hline 66 & Software reuse & $\begin{array}{l}\text { An author's research software impact is in the top n\% of } \\
\text { all research software creators on Depsy }\end{array}$ \\
\hline 67 & Wikitastic & $\begin{array}{l}\text { Times an author's works are mentioned on Wikipedia. } \\
\text { Percentile is also displayed. }\end{array}$ \\
\hline
\end{tabular}

$\begin{array}{cc}\text { Various sources } & I M P^{* * *} \\ \text { Various sources } & I M P^{* * *} \\ \text { Various sources } & I M P^{* * *} \\ \begin{array}{c}\text { blog, FCB, G+, Pinterest, } \\ \text { Reddit, Sina Weibo, } T W, \\ \text { WK }\end{array} & A L T, I M P^{* *}, P L U M \\ \begin{array}{c}\text { Selected sources by } \\ \text { altmetric.com } \\ \text { Various sources } \\ C R, P M C\end{array} & A L T^{*} \\ T W & I M P^{* * *} \\ I M P, S L I, T W & A L T^{*} \\ F C B, L K, Y T & T W \\ D E P & I M P^{*}, S L I, T W \\ W C B, L K, Y T \\ W K\end{array}$

\section{RATING}

$\mathbf{N}$ INDICATOR

\begin{tabular}{|c|c|}
\hline 68 & All readers welcome \\
\hline 69 & Dislikes (automatic) \\
\hline 70 & Expertise \\
\hline 71 & Favorites (automatic) \\
\hline 72 & $\begin{array}{l}\text { Likes } \\
\text { (automatic) }\end{array}$ \\
\hline 73 & $\begin{array}{l}\text { Likes } \\
\text { (manual) }\end{array}$ \\
\hline 74 & $\begin{array}{l}\text { Post-publication peer- } \\
\text { reviews }\end{array}$ \\
\hline 75 & Reviews \\
\hline 76 & Rates/Stars \\
\hline 77 & Recommendations \\
\hline 78 & Recommended by \\
\hline 79 & Skills \\
\hline 80 & Score \\
\hline 81 & $\begin{array}{l}\text { Votes } \\
\text { (manual) }\end{array}$ \\
\hline 82 & +1 votes \\
\hline
\end{tabular}

An author's writing has a reading level that is easily understood at grade $n$ and above, based on its abstracts and titles

Times a video has been disliked (thumbs down) Users that vouch for your skills

Times an author's documents are marked as favorites

Times an author's items have been liked (thumbs up, heart button)

Likes (thumbs up) received, aggregated from article-level metrics

Open reviews to documents already published

Documents that have been reviewed in F1000

Graded ratings (numeric or not) received by an author

Times an author's documents have been recommended

People that recommend an author

Skills that can be validated by other users

Positive votes minus negative votes

Votes received, aggregated through article-level metrics

Times an author's documents have been upvoted $(+1)$

\section{SOURCE OF DATA}

PLATFORM DIPLAYING THE DATA

$\begin{array}{cc}\text { Various sources } & I M P^{* * *} \\ Y T & I M P^{*} \\ L K, R G & \\ S L I, Y T & S L I, I M P^{*} \\ V I, Y T, T W & I M P^{*}, T W\end{array}$

$F C B, L K, S L I, Y T$

$F C B, L K, S L I, Y T$

Publons/Pubpeer

$\mathrm{ALT}^{*}$

F1000

$I M P^{*}$

$A Z, G H, G D R$, SourceForge

FIG, SourceForge

PLUM, GH, IMP*

$L K$

PLUM

$L K, R G$

$L K$

$L K, R G$

Reddit

PLUM

Scirate

Scirate

G+

PLUM 


\begin{tabular}{|c|c|c|c|c|}
\hline \multirow[b]{2}{*}{$\mathbf{N}$} & \multicolumn{4}{|c|}{ SOCIAL CONNECTIVITY } \\
\hline & INDICATOR & DEFINITION & SOURCE OF DATA & $\begin{array}{l}\text { PLATFORM DIPLAYING } \\
\text { THE DATA }\end{array}$ \\
\hline 83 & Answers & $\begin{array}{l}\text { Answers an author sends to questions posed by other } \\
\text { users }\end{array}$ & $R G$ & $R G$ \\
\hline 84 & Contacts & Contacts of an author & $L K$ & $L K$ \\
\hline 85 & Collaborators & Collaborators in a document & GH & PLUM \\
\hline 86 & $\begin{array}{l}\text { Followed } \\
\text { publications }\end{array}$ & Documents an author follows & $R G$ & $R G$ \\
\hline 87 & $\begin{array}{l}\text { Followers/ } \\
\text { subscribers }\end{array}$ & $\begin{array}{l}\text { Users that follow the publications of an author in a given } \\
\text { platform }\end{array}$ & $\begin{array}{c}A C A, G H, L K, M E N D, R G S L I, \\
T W, Y T\end{array}$ & $\begin{array}{c}A C A, L K, M E N D, P L U M, R G \\
S L I, T W, Y T\end{array}$ \\
\hline 88 & Following & Users the author follows & $\begin{array}{c}A C A, L K, M E N D, R G S L I, \\
T W, Y T\end{array}$ & $\begin{array}{l}A C A, L K, M E N D, R G S L I \\
T W, Y T\end{array}$ \\
\hline 89 & Questions & Questions posed by an author & $R G$ & $R G$ \\
\hline 90 & Subscribers & Users that have subscribed to an author's updates & $V I, Y T$ & PLUM \\
\hline 91 & Watchers & $\begin{array}{l}\text { Users that want to be notified when an author makes } \\
\text { changes to a project }\end{array}$ & GH & PLUM \\
\hline
\end{tabular}

\section{COMPOSITE INDICATORS}

INDICATOR DEFINITION

PLATFORM DIPLAYING THE DATA

92

Engagement rate

93 RG Score
Interactions of any kind that users have with an author's publications, divided by the total number of impressions

Combines bibliometric indicators (articles published, citations received), usage indicators (visualizations, downloads), social activities in the platform (making and answering questions), and connectivity measures (followers and following other users)

Automatic: the platform displays this specific author-level metric automatically

Manual: the platform provides an article-level metric, requiring manual aggregation to obtain an author-level metric

IMP* Discontinued on April 2016. At the moment, only old ImpactStory profile display this metric.

IMP** Online mention metric used to calculate achievements.

IMP*** New achievement metric. Available since April 2016 on the new Impactstory profiles.

According to the nature of the indicators and their function in the process of scientific and academic communication, we have classified them into six groups, plus an additional seventh group that combines elements of the other six:

\section{A. Publication}

We consider the concept of publication in its broadest sense. That is, making any kind of document accessible to the public by any kind of communication channel. Therefore, it includes the publication of a book or a journal article, but also the publication of a presentation, software, dataset, or even a tweet in any kind of media outlet. All metrics concerning the number and typology of documents published are included in this group.

\section{B. Citation}

This category contains all the indicators based on citation counts, including the total citation counts provided by several databases and platforms (Web of Science, Scopus, ResearchGate, Academia.edu, RePEc, PubMed Central), citation averages (by year, by article), and the number of citations segregated by the document type where the citation was made (publishers or review articles). This section also includes the various versions of the $\mathrm{h}$-index that are available throughout all academic profile platforms.

\section{Usage}

This group includes all metrics related to the direct use of documents or personal profiles by any kind of user. Principal among them are: visualizations (of the abstracts or documents), and downloads (of the bibliographic reference or full-text of the document in any format). We also include some other types of interactions with the scientific production of an author, like user tags for documents.

Journal articles are not the only documents that make an impact on academia. There are other kinds of documents that may potentially have a quantifiable impact in the academic world (presentations, software, datasets, etc.)

\section{Dissemination, comments, discussion}

This section includes all indicators that measure the extent to which the documents published by an author circulate and spread through other channels of communication, whether it be in the form of a reply to a message or a document, or a comment that discusses the document. Therefo- 
re, here we will include comments, mentions, retweets, or the number of times documents are shared. Certainly, this section groups actions of different natures. Simply disseminating a document is not the same as disseminating it while also facilitating future comments, reviews, or open discussion about the document. Unfortunately, it is still difficult to automatically differentiate whether a blog or tweet only repeats what others have said, or if it adds new comment and criticism. This forces us to group together all these indicators. The day it is possible to differentiate between them, they should be studied separately.

There are 93 indicators listed, a considerable number considering this is still an emerging field; and this list is far from being complete

\section{E. Ratings}

This group includes indicators in which the user explicitly makes a value judgment about an author's work. It ranges from the popular "like", favorites, numeric scores, to recommendations.

\section{F. Social connectivity}

This section groups metrics that indicate the extent to which an author is connected with the rest of the scientific, academic, or professional communities that surround him, and even with the society in general. Therefore, here we are talking about user-user interactions (followers/following, number of contacts), or questions and answers.

\section{G. Composite indicators}

Here we group metrics that summarize various indicators into a single number. For example, the $R G$ Score from $R e$ searchGate, which takes into account a wide variety of metrics, although it has not been disclosed exactly which (Orduña-Malea; Martín-Martín; Delgado-López-Cózar, 2016).
93 indicators are listed, a considerable number considering this is still an emerging field. Still, this list is far from being complete. Many more indicators that measure scientific activity can be found in other services, and they are already being collected by several organizations with an interest in altmetrics: Altmetric.com ${ }^{7}$ and Plum Analytics ${ }^{8}$, both founded in 2011. These platforms, although not originally oriented towards author-level metrics, now have launched some services that make it easier to obtain them (Explorer for institutions, and Plumx dashboards respectively). In many cases, the originality does not lie in the metric itself, but in the source used to collect it. These metrics can also be found in table 1 , which aims to provide as exhaustive a list of $A L M e-$ trics as possible.

\section{The scientific duties of a researcher}

This multiplicity of indicators allows us to measure many different sides of academic life. In this sense, it is important to define the basic aspects of an author's intellectual life that ALMetrics are able to reflect. In an effort to reduce the multidimensionality of the scientific enterprise, we find three general aspects: production, visibility, and impact:

\section{A. Activity}

Deals with the ability of an author to generate new knowledge in the broadest sense of the word. An author may generate information, messages, documents, data, software, patents, designs, etc. Activity is also related to the degree of specialization of the author, since it is obvious that one author cannot be active in all the facets of intellectual production.

\section{B. Visibility}

Is related to the activity of an author that is apparent and manifest. That is, the production that can be observed because it has been made public in some form on the Web. Therefore, it measures the degree to which the production of an author is visible and accessible to the community.

Table 2. Classification of author metrics in the three dimensions of scientific enterprise

\begin{tabular}{|c|c|c|c|c|c|c|c|c|c|c|}
\hline \multirow{2}{*}{$\frac{\text { Activity }}{1}$} & \multicolumn{5}{|c|}{ Visibility } & \multicolumn{5}{|c|}{ Impact } \\
\hline & 1 & 31 & 47 & 61 & 79 & 11 & 25 & 39 & 62 & 79 \\
\hline 2 & 2 & 32 & 48 & 62 & 83 & 12 & 26 & 40 & 63 & 80 \\
\hline 5 & 5 & 33 & 49 & 63 & 84 & 13 & 27 & 41 & 64 & 81 \\
\hline 6 & 6 & 34 & 50 & 64 & 87 & 14 & 28 & 42 & 65 & 82 \\
\hline 7 & 7 & 35 & 51 & 65 & 89 & 15 & 29 & 43 & 69 & 84 \\
\hline 8 & 8 & 36 & 52 & 67 & 92 & 16 & 30 & 44 & 70 & 85 \\
\hline 9 & 9 & 37 & 53 & 68 & & 17 & 31 & 45 & 71 & 87 \\
\hline 10 & 10 & 38 & 54 & 70 & & 18 & 32 & 46 & 72 & 90 \\
\hline 61 & 17 & 39 & 55 & 71 & & 19 & 33 & 47 & 73 & 91 \\
\hline 83 & 26 & 40 & 56 & 72 & & 20 & 34 & 49 & 74 & 92 \\
\hline 84 & 27 & 41 & 57 & 73 & & 21 & 35 & 50 & 75 & 93 \\
\hline 86 & 28 & 43 & 58 & 74 & & 22 & 36 & 53 & 76 & \\
\hline 88 & 29 & 44 & 59 & 75 & & 23 & 37 & 59 & 77 & \\
\hline 89 & 30 & 46 & 60 & 78 & & 24 & 38 & 60 & 78 & \\
\hline
\end{tabular}




\section{Impact}

Deals with the repercussions of an author's production: intellectual footprint; influence in the scientific, academic, professional communities; and usefulness to society in general.

Table 2 shows the metrics that can be associated with each of these dimensions.

In regards to the intellectual impact of production, we should warn that impact may occur in diverse situations, which should be commented on individually to avoid misunderstandings. These situations are determined by the communities to which these intellectual products are targeted. One should distinguish between the scientific, professional, educational, political, and media communities. Thus, we could also speak about scientific, professional, educational, political, and media impact (figure 3). Each metric may be related to one or more of these kinds of impact.

The multiplicity of indicators allows us to measure many different sides of academic life

Many of these indicators have already been integrated into databases (Scopus), journal publishing platforms (BioMedCentral, HighWire), prestigious publishers (Nature Publishing Group), and journals (PloS one), which demonstrates the quick penetration of these indicators in the scientific community.

However, the indicators are not being used to their full extent for two reasons: a) they are being implemented within a small subset of the scientific literature (Priem et al 2013, Robinson-García et al., 2014; Delgado-López-Cózar; MartínMartín, 2016); and b) there are still many users that ignore

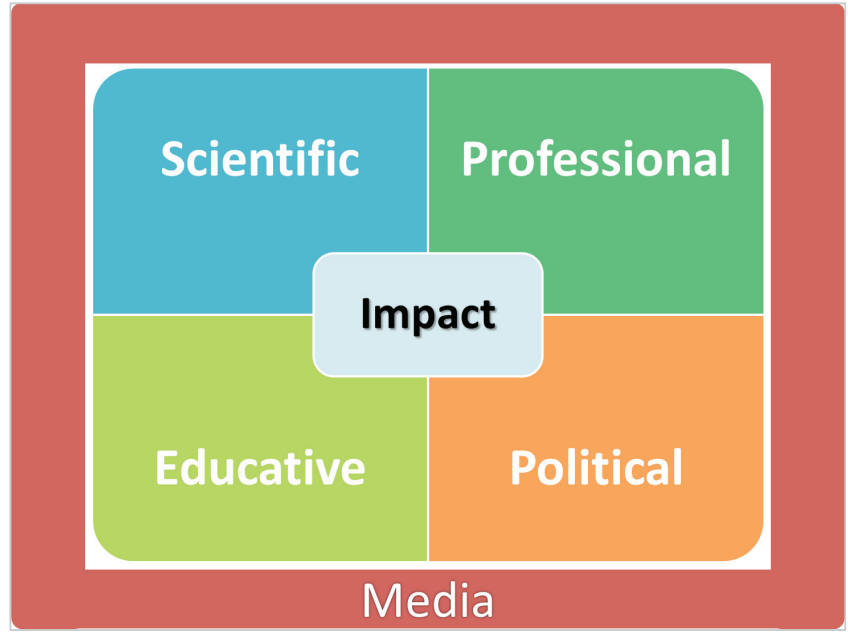

Figure 3. Types of intellectual impact

their existence, or who do not see them in a positive light (Habid, 2013; Priem et al., 2013; Van-Noorden, 2013; Haustein et al., 2014). Nevertheless, the public opinion seems to be rapidly shifting (Taylor \& Francis, 2014; Kramer; Bosman, 2015; DeSanto; Nichols, 2016).

Among the new sources of scientific information and tools for scientific evaluation, Google Scholar is used the most (Gardner; Inger, 2013; Orduña-Malea et al., 2014; Kramer; Bosman, 2015; Martín-Martín et al., 2016), followed by ResearchGate. Among the new bibliometric indicators, the $\mathrm{h}$ index is the one most well-known and used, although the number of downloads is also widely accepted (Habid, 2013; Haustein et al., 2014).

Two products developed by the EC3 Research Group can be considered an empirical example of the new ALMetricsbased bibliometrics: La Biblioteconomía y Documentación española según Google Scholar Citations ${ }^{9}$, which was later

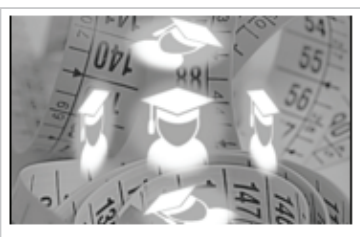

\section{Scholar Mirrors}

Bibliometrics, Scientometrics, Informetrics, Webometrics, and Altmetrics in Google Scholar Citations, ResearcherlD, Researchgate, Mendeley, and Twitter

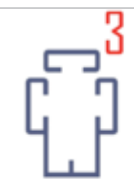



Figure 4. ALMetrics in Scholar Mirrors

http://www.scholar-mirrors.infoec3.es 
refined into Scholar Mirrors ${ }^{10}$, a genuine fusion of new sources, mirrors, and indicators (Martín-Martín et al., 2016).

\section{Final conclusion}

The use of these measures as new mirrors in which authors can look at themselves is the foundation of the new ALMetrics: the assessment of all dimensions and sides of an author's scientific performance through metrics (Author Level Metrics) available in new sources. In conclusion, nowadays everything can be measured in science, and in fact it is being measured. This trend will coexist for a while with the traditional journal-level evaluation, until the latter ends up disappearing like a sugar lump in water.

The new trend will coexist for a while with the traditional journal-level evaluation, until the latter ends up disappearing like a sugar lump in water

Nevertheless, the path towards new metrics and platforms is treacherous and passes through unknown territory. For example, ImpactStory (one of the leading ALMetrics platforms) implemented changes on the $8^{\text {th }}$ of April 2016, just as this manuscript was completed. Impactstory, one of the main players in the field of ALMetrics, has completely rebuilt its platform: the new user profiles use data from Orcid profiles as the main source of information, and at the moment indicators are attached only to documents with a DOI. Moreover, it no longer displays citation-based indicators $^{11}$, a remarkable change for a product that has always been considered alternative. This renovation has also brought a redefinition of its impact dimensions (buzz, engagement, and openness) in which indicators (now called achievements, also included in table 1) are grouped, all of them based on social metrics (table 1). Unfortunately, the way impacts are calculated is still not completely transparent, which affects the replicability of the results (just like is the case with the RG Score) and keeps us from being able to carry out a precise analysis of its usefulness and meaning in evaluative terms. ResearchGate is also widely known to make significant changes on an almost weekly basis.

As we warned in previous studies (Delgado-López-Cózar, 2014), the new bibliometrics is still unstable: measures, indicators, and platforms are volatile, fleeting. It is difficult to reproduce them, if not downright impossible, when they suddenly stop being supported.

In spite of everything, the new bibliometrics have a bright future. And, as Robert K. Merton wisely taught us, it all comes from the desire scientists have for knowledge, and especially nowadays, for acknowledgement. It is the ego that is at stake here (Martín-Martín; Orduña-Malea; DelgadoLópez-Cózar, 2016).

\section{Notes}

1. $h t t p: / / w w w . a s c b . o r g / d o r a$

2. http://citec.repec.org/p/index.html

3. http://futur.upc.edu

4. https://impactstory.org

5. https://en.wikipedia.org/wiki/Author-level_metrics

6. http://altmetrics.org/manifesto

7. https://www.altmetric.com

8. http://plumanalytics.com

9. http://www.biblioteconomia-documentacion-española. infoec3.es

10. http://www.scholar-mirrors.infoec3.es

11. http://blog.impactstory.org/new-better-freer

\section{References}

Das, Anup-Kumar (2015). Research evaluation metrics (mod. 4). Unesco Publishing.

http://unesdoc.unesco.org/images/0023/002322/232210E.pdf

Delgado-López-Cózar, Emilio (2014). “La nueva bibliometría: nuevos horizontes, nuevas oportunidades, nuevos peligros. Vino viejo en odre nuevo". EC3noticias, 11 abril. http://ec3noticias.blogspot.com.es/2014/04/la-nuevabibliometria-nuevos-horizontes.html

Delgado-López-Cózar, Emilio; Martín-Martín, Alberto (2015). Thomson Reuters coquetea con las altmetrics: usage counts para los artículos indizados en la Web of Science. Granada: EC3 Working papers, 20.

http://hdl.handle.net/10481/38281

DeSanto, Dan; Nichols, Aaron (in press). "Scholarly metrics baseline: A survey of faculty knowledge, use, and opinion about scholarly metrics". College \& research libraries.

http://crl.acrl.org/content/early/2016/02/25/crl16-868. abstract

Flenley, Neil (2016). Innovations in scholarly communication: results from the survey of Emerald authors. Emerald Group.

http://www.emeraldgrouppublishing.com/promo/pdf/ scholarly_communication.pdf

Gardner, Tracy; Inger, Simon (2013). How readers discover content in scholarly journals. Comparing the changing user behaviour between 2005 and 2012 and its impact on publisher web site design and function. Abingdon: Renew Training. ISBN: 9780957392045

http://digitalcommons.unl.edu/scholcom/13

Garfield, Eugene (2006). "The history and meaning of the journal impact factor". JAMA, v. 295, n.1, pp. 90-93. http://garfield.library.upenn.edu/papers/jamajif2006.pdf

Garfield, Eugene; Sher, Irving H. (1963). “New factors in the 
evaluation of scientific literature through citation indexing". American documentation, v. 14, n. 3, pp. 195-201. http://www.garfield.library.upenn.edu/essays/v6p492y1983. $p d f$

Habib, Michael C. (2013). Measure for measure: The role of metrics in assessing research performance. Society for Scholarly Publishing.

http://www.slideshare.net/habibmi/ssp-metrics-mch2

Haustein, Stefanie; Peters, Isabella; Bar-Ilan, Judith; Priem, Jason; Shema, Hadas; Terliesner, Jens (2014). "Coverage and adoption of altmetrics sources in the bibliometric community". Scientometrics, v. 101, n. 2, pp. 1145-1163.

http://dx.doi.org/10.1007/s11192-013-1221-3

Hirsch, Jorge E. (2005). "An index to quantify an individual's scientific research output". Proceedings of the National Academy of Sciences of the United States of America, v. 102, n. 46, pp. 16569-16572.

http://dx.doi.org/10.1073/pnas.0507655102

Kramer, Bianca; Bosman, Jeroen (2015). "101 innovations in scholarly communication - the changing research workflow" [poster].

https://dx.doi.org/10.6084/m9.figshare.1286826.v1

Martín-Martín, Alberto; Orduña-Malea, Enrique; Ayllon, Juan M.; Delgado-López-Cózar, Emilio (2016). The counting house: measuring those who count. Presence of bibliometrics, scientometrics, informetrics, webometrics and altmetrics in the Google Scholar Citations, ResearcherID, ResearchGate, Mendeley \& Twitter. EC3 Working papers, 21. http://arxiv.org/pdf/1602.02412

Martín-Martín, Alberto; Orduña-Malea, Enrique; DelgadoLópez-Cózar, Emilio (2016). The role of ego in academic profile services: Comparing Google Scholar, ResearchGate, Mendeley, and Researcherid. London School of Economics and Political Science, March 4.

http://blogs.Ise.ac.uk/impactofsocialsciences/2016/03/04/ academic-profile-services-many-mirrors-and-faces-for-asingle-ego

Mohammadi, Ehsan; Thelwall, Mike (2014). "Mendeley readership altmetrics for the social sciences and humanities: Research evaluation and knowledge flows". Journal of the Association for Information Science and Technology, v. 65, n. 8 , pp. $1627-1638$

http://dx.doi.org/10.1002/asi.23071
Orduña-Malea, Enrique; Ayllon, Juan M.; Martín-Martín, Alberto; Delgado-López-Cózar, Emilio (2014). "The silent fading of an academic search engine: the case of Microsoft Academic Search". Online information review, v. 38, n. 7, pp. 936-953.

http://dx.doi.org/10.1108/oir-07-2014-0169

Orduña-Malea, Enrique; Martín-Martín, Alberto; DelgadoLópez-Cózar, Emilio (2016). "ResearchGate como fuente de evaluación científica: desvelando sus aplicaciones bibliométricas". El profesional de la información, v. 25, n. 2, pp. 303310.

http://dx.doi.org/10.3145/epi.2016.mar.18

Priem, Jason; Piwowar, Heather A.; Hemminger, Bradley M. (2012). "Altmetrics in the wild: Using social media to explore scholarly impact".

http://arxiv.org/abs/1203.4745

Robinson-García, Nicolás; Torres-Salinas, Daniel; Zahedi, Zohreh; Costas, Rodrigo (2014). "New data, new possibilities: Exploring the insides of Altmetric.com". El profesional de la información, v. 23, n. 4, pp. 359-366.

http://dx.doi.org/10.3145/epi.2014.jul.03

Seglen, Per O. (1997). "Why the impact factor of journals should not be used for evaluating research". BMJ: British medical journal, v. 314, n. 7079, pp. 498-502.

http://dx.doi.org/10.1136/bmj.314.7079.497

Taylor \& Francis (2014). Open access survey: examining the changing views of Taylor \& Francis authors.

http://www.tandfonline.com/page/openaccess/ opensurvey/2014

Van-Noorden, Richard (2014). “Online collaboration: Scientists and the social network". Nature, v. 512, n. 7513, pp. 126-129.

http://dx.doi.org/10.1038/512126a

Wildgaard, Lorna (2015). "A comparison of 17 author-level bibliometric indicators for researchers in astronomy, environmental science, philosophy and public health in Web of science and Google scholar". Scientometrics, v. 104, n. 3, pp. 873-906.

http://dx.doi.org/10.1007/s11192-015-1608-4

Wildgaard, Lorna; Schneider, Jesper W.; Larsen, Birger (2014). "A review of the characteristics of 108 author-level bibliometric indicators". Scientometrics, v. 101, n. 1, pp. 125-158. http://dx.doi.org/10.1007/s11192-014-1423-3



